\title{
SUJECIÓN LABORAL Y CONFLICTOS JURISDICCIONALES EN UNA COMUNIDAD MAM DEL ALTIPLANO GUATEMALTECO (1890-1947)
}

\author{
Rosa Torras Conangla \\ Doctorante en Estudios Mesoamericanos de la UNAM
}

\begin{abstract}
RESUMEN
La entrada de Guatemala en la economía de agroexportación cafetalera en el siglo XIX supuso la aplicación de diversos mecanismos de sujeción laboral destinados a movilizar a los trabajadores — sobre todo indígenas - de las zonas donde residían a aquellas donde se producía el cultivo. Las fincas de mozos fueron uno de esos mecanismos. El presente artículo $^{1}$ explora los efectos de estas políticas en una comunidad mam del altiplano huehueteco, mismas que provocaron altos índices de conflictividad expresados en desmembramientos territoriales y conflictos jurisdiccionales.
\end{abstract}

\section{EL “PROBLEMA DE LA MANO DE OBRA” PARA LA ECONOMÍA}

\section{AGROEXPORTADORA}

A mediados de 2001, un anciano del caserío El Chorro —aldea Xémal, municipio de Colotenango, departamento de Huehuetenango, fronterizo con el estado de Chiapas, México- contaba por qué se veía todavía obligado a trabajar en las fincas cafetaleras. $\mathrm{Su}$ relato constituye un testimonio de la permanencia, en el tiempo largo, del trabajo forzado en el agro guatemalteco por medio de las denominadas "fincas de mozos". 
Fui otra vez a la finca, ¿por qué?, por el motivo del agua ... [Me] estoy dando cuenta de que como fue antes, igual está sucediendo ahora, es igual. Volví otra vez. Sí, a mi edad, hasta voy a ir en estos días, pues tenía mi caña, unas cuantas cuerdas, entonces había un agua de riego de la comunidad. Pero el nacimiento no es de la comunidad, es de la finca Rosario. Entonces esa finca está obligando que se vayan; los que están usando esa agua a pura ley se tienen que ir a la finca a cortar su café. Y si no van a la finca les quitan el agua. Eso es ahora. ... Esa finca tiene cafetaleras, esos son finqueros. Y esa finca Rosario tiene finca aquí arriba. No sé cómo se llama esa finquita que está arriba. Es el mismo dueño, pero allí no tiene cafetaleras solo gente está allí, pues; siembran la gente milpa pero el dueño es de Guate [ciudad de Guatemala]. Sí,. es el mismo dueño. La finca Rosario está en la costa y es el dueño [de la] que está arriba [La Sierra]. La gente puede tener su milpa. Para mi caña tengo que ir al Rosario, tengo que ir a cortar café y si no voy pues me quitan el agua, me quedo sin agua. Toda la comunidad tiene este problema. Cuando yo miro que en el tiempo de fines de octubre de aquí salen unas ocho camionadas de gente. Para las costas, para cortar café, en esa finca. Sí, todos, los de Xémal, los de Chorro no, porque ellos no usan esa agua. El agua es para Xémal. Cuando ellos van a la finca les pagan 25 quetzales cada caja de café. No es gratis, pero si no vas a la finca te quitan el agua. Mi caña está en Xémal y estoy usando esa agua. Siempre tengo que ir a la finca; ¿por qué razón?, pues, es por el agua. Si no hay agua no hay cosecha, porque tengo cañas. La finca, pues, es obligado ir a la finca. Si no, el que no va a la finca le quitan el agua, y si no va toda la comunidad, pues, la finca tiene derecho de vender en otro lugar y ya la comunidad se queda sin agua. ${ }^{2}$

Don Juan, un campesino mam que tenía 73 años cuando le entrevisté, describía con claridad la situación del momento: contaba cómo los pobladores de la aldea Xémal, ubicada en las faldas de la sierra de los Cuchumatanes, tienen la obligación de ir a cortar café a la finca El Rosario, en la bocacosta guatemalteca, a una distancia aproximada de 140 kilómetros por carretera. Es la forma de pago por el derecho a utilizar el agua, cuyo nacimiento se encuentra en la finca La Sierra, situada en Xémal. Ambas fincas son del mismo propietario. Asimismo, las familias mames que viven y cultivan maíz en la última pueden hacerlo a cambio de ir a trabajar a El Rosario.

Esa realidad, vigente hasta la fecha, es una pequeña muestra de las formas de sujeción laboral tejidas desde antaño, concretamente desde el tiempo en que Guatemala adoptó 
como modelo la economía agroexportadora cafetalera, ahondando la marginalización de muchos pueblos indígenas del altiplano guatemalteco. Pueblos que no vivían en zonas productoras de café, pero que fueron insertados en ese sistema económico a partir de la extracción de un recurso indispensable para que funcionara: su fuerza de trabajo.

Fueron bastantes los mecanismos utilizados por el Estado para forzar la movilidad laboral, pero don Juan alude a uno poco estudiado y mucho más común de lo que puede parecer: las denominadas fincas de mozos. Sabemos poco de ellas porque no han sido reguladas en la legislación laboral, por tanto, no aparecen de forma explícita en registros agrarios o memorias de gobierno. Ello hace que para rastrearlas sea necesario diversificar las fuentes históricas y acercar el lente al detalle, además, así como en Guatemala cada vez hay más estudios que develan esa forma de colonato a distancia, queda pendiente saber si también existieron o existen en países vecinos.

El presente artículo pretende, por lo comentado, analizar desde un enfoque microhistórico y a partir de las fuentes oral y escrita, cómo afectó a una comunidad mam del altiplano la inserción de Guatemala en la lógica económica cafetalera, creando mecanismos de sujeción laboral que posibilitaron la movilización hacia las fincas de la bocacosta y la costa de la mano de obra ubicada en zonas no productoras de café. Para ello, fue necesario crear y aplicar un cuerpo de leyes que adecuara la existencia del trabajo forzado, al mismo tiempo que se impulsaba la expropiación legal e ilegal de tierras comunales en los pueblos indígenas, con el fin de hacer cada vez más difícil la sobreviviencia comunitaria y provocar la expulsión de mano de obra. 
La lucha tenaz de los pobladores por el control de sus recursos comunitarios se expresó en muchas ocasiones a través de conflictos jurisdiccionales, pues la municipalidad era el ente local que regulaba el trabajo forzado y hacía posible resistirse a la pérdida de tierras ocasionada por la incursión de los $\operatorname{ladinos}^{3}$ — también extranjeros—, quienes durante el siglo XIX se expandieron de forma contundente en las zonas indígenas, que habían conservado su patrimonio durante el periodo colonial.

Ante el creciente problema que enfrentaban los finqueros de cómo volver "disponible" para las fincas cafetaleras la fuerza laboral que se encontraba lejos de ellas, se profundizó la búsqueda de trabajadores en las tierras del altiplano y, para esto, se perfeccionó el sistema coactivo de trabajo, desde mediados del siglo XIX hasta 1947, año en que se emitió el Código de Trabajo.

A partir de la Revolución liberal de 1871, tres momentos legislativos marcaron ese proceso: la legislación producida por los liberales a partir de la herencia conservadora — con algunos ajustes de parte de los gobiernos siguientes - que se cristalizó en el Reglamento de jornaleros, de 1877 , complementado con la Ley contra la vagancia de 1878. Luego, la dictada por el general Jorge Ubico a partir de 1931, en plenos efectos de la crisis económica mundial, que implicó la abolición en 1934 del peonaje por deudas y un reacomodo del sistema de trabajo forzado sobre la lógica de la vagancia. Y finalmente, con la emisión del Código de Trabajo de 1947 por parte del gobierno revolucionario de Juan José Arévalo, se instaura la obligación del pago de salario a los trabajadores del campo y la abolición de los mecanismos de coacción extraeconómica legal. No obstante, como vemos en el caso descrito por don Juan, las formas de sujeción 
laboral se perpetuaron de forma extralegal. En el presente artículo, a pesar de aportarse datos que dejan constancia de la continuidad hasta la actualidad de muchos de los fenómenos investigados, me centraré en el periodo en que dichas formas se consolidaron bajo el impulso estatal (1890-1947).

La ideología liberal fue conformándose alrededor de concebir al indígena como "mozo", pues en su trabajo debía recaer el aparato productivo del país. En la "Memoria" de la Dirección General de Agricultura de 1901 se describían de la siguiente manera las ventajas del indígena como trabajador:

La mayor parte de los trabajadores que se emplean en la agricultura son indígenas del país. Las condiciones de éstos para las faenas rudas del campo, no han podido encontrarse ni en la clase llamada ladina ni en trabajadores traídos de otras partes (polineses, negros y japoneses). El indio es frugal y sobrio en extremo: se contenta con poco para vivir y en cambio resiste bien el clima de las costas, trabaja con ardor, y las enfermedades no hallan presa fácil en su constitución vigorosa. Esto depende del trato que se le dé. El indígena a fuerza de sufrir ha tomado horror al trabajo de las fincas, pero hallándose en una parte contento hace con gusto su tarea, trabaja doble y pide muy poca remuneración. ${ }^{4}$

Reconocida esta realidad por las autoridades gubernamentales, es obvio que tanto las políticas estatales como la práctica de los finqueros se enfocó en convertir la zona del altiplano guatemalteco — donde se concentraba la mayoría de la población indígena— en "semilleros" de mano de obra para las fincas de la bocacosta del país. El hecho de calificar a esa población de forma ambivalente, les permitía siempre adecuar una justificación para extraer su fuerza laboral.

En 1907, Arzú Batres ya denunciaba los desastrosos efectos causados en la población de estos lugares por el trabajo en las fincas: 
Y la experiencia lo confirma; continuamente encontramos en los pueblos altos, viejos decrépitos de 40 años; se les pregunta qué tienen, de qué sufren, y contestan con su tranquilidad inalterable: “ya no hay tu fuerza, Tata, se acabó en la finca”. Huyendo de los mandamientos y de las mil vejaciones que las autoridades locales les hacen sufrir en los pueblos, muchos, muchísimos indios, se remontan a las montañas prefiriendo las penalidades del aislamiento, la tristeza de la soledad, a las amarguras de la esclavitud disfrazada; pero no les vale; tras el indio fugitivo que se oculta va el ladino a denunciar como baldío el monte en que se ampara. Al titular el terreno, queda el indio en calidad de colono permanente. ... El de Huehuetenango, fronterizo con México, gana, por lo menos ganaba hasta el año 1904, 18 pesos anuales y la ración, ración que consiste en maíz, frijol y sal. Pero a cuenta del derecho de sembrar en la finca, paga un impuesto o baldiaje, como allá se llama, que consiste en trabajar gratis en la preparación del terreno, siembra, deshierbo y recolección de tapizca o del maíz y frijol de la hacienda ... en cambio, el jornal efectivo del mozo es de cinco centavos diarios pagaderos por anualidades vencidas; y como durante el año algún dinero ha necesitado ... resulta que en cada liquidación que se hace, debe algo más y tiene algunas menos posibilidades de emanciparse legalmente de la tutela del patrón. ${ }^{5}$

Pero centrémonos en uno de los mecanismos de extracción laboral, fruto de la audacia de los finqueros bajo la permisividad gubernamental: las fincas de mozos.

\section{LAS FINCAS DE MOZOS: UNA “RESERVA” DE FUERZA LABORAL EN EL ENGRANAJE AGROEXPORTADOR}

Las fincas de mozos se fueron conformando por la práctica de los finqueros de comprar terrenos no aptos para los cultivos de agroexportación, en los que rentaban parcelas a los indígenas de la zona a cambio de mano de obra estacional en sus fincas cafetaleras o cañeras de la vertiente del Pacífico. Una forma de colonato a distancia que no estaba recogida en los documentos oficiales; por lo que queda pendiente llevar a cabo un registro sistemático que nos permita conocer el alcance de esta práctica en todo el país. 
Sabíamos de su existencia por estudios de caso como el de David McCreery, quien encontró fincas de mozos en San Juan Ixcoy (Huehuetenango), propiedad de las fincas cafetaleras Helvetia (Quetzaltenango) y El Perú (San Marcos) ${ }^{6}$, donde también eran habilitados los mames de Colotenango. Otra investigación analizó la relación entre la finca de mozos Canajal de 69 caballerías (3,105 ha aprox.) proveedora de mozos y la finca azucarera El Baúl (Escuintla) ${ }^{7}$; mientras que el trabajo de Lizeth Jiménez ${ }^{8}$ estudia otra finca más perteneciente también a El Baúl, llamada Chuacorral y ubicada en Joyabaj (Quiché). Por su parte, Matilde González analizó las fincas de mozos en San Bartolomé Jocotenango (Quiché) pertenecientes a la Compañía Holandesa de Comercio C.A. ${ }^{9}$ Mientras que Mario Tejada menciona aquellas que la familia alemana de cafetaleros Nottebohn tenía en la cumbre de los Cuchumatanes, concretamente en San Juan Ixcoy. ${ }^{10}$

El caso que nos ocupa es el de la finca La Sierra en San Rafael Pétzal (Huehuetenango), llamada "anexo a El Rosario", por ser finca de mozos de la finca cafetalera El Rosario ubicada en El Tumbador (San Marcos). San Rafael Pétzal es un municipio que se formó a partir de la división del municipio de Colotenango en dos; segregación impulsada por ladinos que habitaban en ese municipio de mayoría mam a finales del siglo XIX, especialmente por los miembros de la familia Aguirre. Estos ladinos llegaron a asentarse en esa zona atraídos por los beneficios del estanco de aguardiente, convirtiéndose en finqueros medios, productores de caña de azúcar.

La Sierra formaba parte de un lote de terreno llamado Tuimaché, declarado exceso en $1897^{11}$ cuando se estaban midiendo los ejidos del recién creado municipio de San 
Rafael Pétzal. Vecinos mames de Colotenango y Pétzal que poseían ese terreno lo habían denunciado, a pesar de ello fue declarado baldío para luego ser vendido en subasta pública. Medía 10 cab $52 \mathrm{mz} 7,600 \mathrm{v}^{2}$ (487 ha y 2 a 36 cta), y fue adquirido por Vicente Marroquín a razón de 36 pesos por caballería. El presidente José M. ${ }^{a}$ Reina Barrios se lo adjudicó en "nombre de la nación”, ordenando al jefe político y demás autoridades que "con ningún motivo ni pretexto perjudiquen ni permitan se moleste al señor Marroquín ni a sus sucesores, en la posesión del enunciado terreno en lo que yo por el presente les amparo”. En enero de 1898 quedó concluida la adjudicación, y en mayo del mismo año Marroquín vendió la propiedad al coronel Tiburcio Molina. ${ }^{12}$ Éste, a su vez, la traspasó a José Mathis en 1919, a quien se la compró en 1925 la alemana Sociedad Buhl y Lange. Una parte de esa finca, 4 caballerías (181 ha), fue desmembrada y registrada como finca La Sierra.

Después de haberse disuelto la Sociedad Buhl y Lange a raíz del fallecimiento del socio Federico Lange —25 de mayo de 1939—, se formó Buhl y Compañía — sociedad constituida por Enrique Buhl y Alberto Hachmeister-, que pasó a ser la dueña de ésta y otras fincas de la zona. Al disolverse la sociedad Buhl y Cía en 1942, le fue adjudicada la finca a Carlota Volheim Muth, viuda de Buhl.

Los datos que existen sobre Enrique Buhl, originario de Hamburgo, indican que llegó a la capital de Guatemala en 1899, donde trabajó con Federico Gerlach —comerciante alemán y principal cafetalero del país en esos años- del que se independizó para fundar una tienda de comestibles. Al quebrar la tienda, se asoció con Federico Lange para crear la ya citada empresa, con sucursales en El Tumbador, Pajapita y la cabecera 
de San Marcos. Asimismo, se dedicó a la importación de artículos de manufactura alemana, petróleo y gasolina de México, y vendía productos del país como azúcar y cerveza. En 1910, la compañía empezó a exportar café de las fincas ubicadas en los municipios El Tumbador, El Rodeo, San Rafael y Nuevo Progreso; a San Francisco, en Estados Unidos. En 1914, Buhl construyó un beneficio de café en Pajapita y, a partir de ese momento, se dedicó exclusivamente al negocio de este producto, ${ }^{13}$ comprando fincas de café en los mismos municipios donde antes solo exportaba el grano. ${ }^{14}$

Por otro lado, el también ciudadano alemán Juan Lüttmann era propietario de la finca cafetalera Nahuatancillo. ${ }^{15}$ Cuando esta fue intervenida en 1918 por orden del gobierno de Manuel Estrada Cabrera una vez finalizada la Primera Guerra Mundial, pasó a ser su interventor interino el compatriota Alberto Hachmeister, quien fundara Buhl y Cía junto a Enrique Buhl.

Paralelamente, Juan Lüttmann y su socio José Mathis compraron la finca cafetalera El Rosario, en el municipio de El Tumbador, la que siguió los mismos cambios de propietario que las fincas huehuetecas Tuimaché y La Sierra. Mathis era, además, propietario de dos fincas urbanas, en el pueblo San Juan Atitán, que vendió sucesivamente a Buhl y Lange en 1925 y a Buhl y Cía en 1939. ${ }^{16}$ Estas dos fincas forman parte, al menos desde 1939, también de la finca El Rosario.

Cuando en 1953 la Comisión Agraria Departamental de Huehuetenango recomendó que se entregara la finca La Sierra a los mozos — después de haber sido expropiada junto con la de Tuimaché ${ }^{17}$ por haber declarado a Carlota Volheim "enemiga de guerra" 
durante la Segunda Guerra Mundial—, se especificaba "que desde hace mucho tiempo, la finca en cuestión ha sido dada a trabajadores sin pago de arrendamientos, sino por compromisos de trabajo a fincas que la propietaria posee en la costa sur del país"18.

Es decir, el valor de la finca en San Rafael Pétzal no estaba en lo que producía su suelo, sino en la mano de obra que albergaba. ${ }^{19}$ Era una finca de mozos, y para sus propietarios, primero guatemaltecos y después alemanes, resultaba ser un área de reserva de fuerza de trabajo para la producción cafetalera.

En 1953 la finca La Sierra fue expropiada y pasó a ser propiedad de la nación cuando fue denunciada por el Comité Agrario Local de San Rafael Pétzal, en aplicación de la Reforma Agraria promulgada por el presidente Jacono Árbenz un año antes. El 6 de enero de 1954 les fue adjudicada a los mozos que trabajaban en ella. ${ }^{20}$ Según datos del 2. ${ }^{\circ}$ Registro de la Propiedad Inmueble ${ }^{21}$, esta finca la heredó el 3 de abril de 1967 Julio Montes Taracena — quien era administrador de Carlota Volheim— junto con Adolfo Frank Klein y Johanna Weingortner. En 1968 Montes compró las partes que eran de estos dos alemanes y el 19 de mayo de 1978 se la vendió a la entidad Agrícola El Rosario, S. A. (Agrirosa), quien es la propietaria actual. No fue posible averiguar los nombres de los titulares de la sociedad anónima, pero según fuentes locales pertenece a la familia Bonifaci Botrán, dueños de una de las más importantes empresas productoras de alcohol, así como de fincas de azúcar y de café. ${ }^{22}$ En 1987 constaba como propietario en un acta de sesiones de la municipalidad de Colotenango, Jaime Bonifás Prat, miembro de la misma familia Bonifaci, de origen catalán. ${ }^{23}$ 
Hoy La Sierra, según testimonios locales como el de don Juan, sigue siendo finca de mozos anexa a El Rosario. Esos mismos testimonios relatan cómo la obligatoriedad de ser mozos en dicha finca no solo afecta a los que usufructúan sus tierras, sino a todos los habitantes de la aldea Xémal que necesitan el agua, cuyo manantial se encuentra en esa misma finca. Consta en el acta municipal de 1987 mencionada, la siguiente petición de los mozos de la finca:

Que el anterior propietario de la finca La Sierra anexo El Rosario les concedió permiso según documentos que obran en poder de la comunidad, para hacer uso de un nacimiento de agua existente en la finca, que en vista de ese permiso efectuaron sus trabajos de agua potable para su aldea, pero los realizaron en forma empírica ... ahora la comunidad se compone de campesinos sumamente pobres, razón por la cual no pudieron efectuar su trabajo de agua potable formal ... pero se cuenta con el problema de que el nuevo dueño de la finca donde está el nacimiento es el señor Jaime Bonifás Prat; precisamente por eso invitaron a la autoridad para pedir permiso a este nuevo dueño, a efecto les autorice el nacimiento de agua. Claro está que todos los vecinos se comprometen a respetar su propiedad, no causando ningún daño. ... Por este mismo acto hacen [los vecinos] formal propuesta y bajo su responsabilidad que esa agua la utilizarán única y exclusivamente para sus servicios domésticos y no para otra cosa, asimismo, los propietarios de los terrenos por donde pasará la tubería al realizarse el proyecto desde este momento dan su permiso para que pase esta tubería.

El recorrido que acabamos de hacer por los propietarios de la finca La Sierra ilustra la inserción de zonas periféricas a los núcleos de producción cafetalera del país, fruto del despojo que ocasionaron altos grados de conflictividad agraria en esas tierras. Veamos a continuación cómo se legalizó el despojo mencionado para analizar, más adelante, sus efectos en la dinámica local. 


\section{INCURSIÓN LADINA Y REORDENAMIENTO TERRITORIAL: CREACIÓN DE UN MUNICIPIO “LADINO”}

Xémal era una aldea ${ }^{24}$ que pertenecía al municipio de Colotenango, pero al ser creado en 1890 el nuevo municipio de San Rafael Pétzal por impulso de los ladinos con mayor poder económico de la zona, resultó incorporada a este último. El nuevo municipio se originaba a partir de la segregación de la aldea Pétzal y de la mitad de los terrenos que formaban parte del municipio de Colotenango. Era una zona propicia para el cultivo de caña de azúcar, propiedad ya controlada por las familias de ladinos que penetraron en el área atraídos por el negocio del aguardiente a mediados del siglo XIX, bajo el régimen conservador. El monopolio cedido por el Estado les benefició ampliamente, en detrimento de la población mam que habitaba el lugar.

El primer propietario ladino en Pétzal fue Nazario Argueta quien, por adjudicación del Estado de Los Altos, en 1839 obtuvo 21 caballerías (543 ha 4 a 2,192 cta) en Pétzal Chiquito. ${ }^{25}$ Como constata Taracena, ${ }^{26}$ en pleno desarrollo del regionalismo altense, los quetzaltecos y sus aliados fueron progresivamente acaparando tierras durante la segunda mitad del siglo XVIII, acentuándose la tendencia de 1800 a 1820, en el tiempo del surgimiento del autonomismo de Los Altos. A partir de 1826, la mayoría de beneficiarios de apropiación de tierras — a través de la figura colonial de la denuncia— fueron después funcionarios importantes del Estado de Los Altos, en perjuicio de las comunidades indígenas. Esta expansión se dirigió sobre todo hacia el litoral del Pacífico —Suchitepéquez y Santo Domingo Retalhuleu—, pero también incluía zonas cálidas de 
Huehuetenango, como la que nos ocupa, que tenían el carácter estratégico de ser punto de paso hacia el territorio chiapaneco.

Argueta vendió la propiedad a José Ríos, principal estanquero de aguardiente de Huehuetenango, lo que le permitió a este convertirse en el mayor propietario de cañaverales de la zona. Ríos, a su vez, emparentó con los Aguirre, quienes llegarían a ser la familia de mayor peso económico en Pétzal, protagonista del proceso de segregación del municipio de Colotenango iniciado legalmente en 1884. En la primera solicitud de la que tenemos constancia, los aldeanos ladinos pedían al jefe político de Huehuetenango segregarse de Colotenango y erigirse en un municipio independiente, por las siguientes razones:

El pueblo de Colotenango, en donde nos encontramos sometidos, se halla a dos leguas distante de Pétzal. Su municipio es de indígenas, ante lo cual los propietarios ladinos de nuestro vecindario no pueden disfrutar de completa y justa administración de justicia por carecer [los indígenas] del despejo y conocimiento necesario para ello. ${ }^{27}$

El secretario de estado de gobernación y justicia apoyó la solicitud, pues consideraba que "esa aldea se ha ido formando de aglomeración de fincas en aquel lugar", lo que confirmaba el peso de la migración ladina altense. Igualmente la avaló el fiscal, quien recomendaba eregirlo "en municipio independiente, conviniendo tal vez suprimir el de Colotenango y agregarlo al de Pétzal”28. Por su parte, el jefe político de Huehuetenango Francisco Fuentes, justificó la petición argumentando lo siguiente: 


\begin{abstract}
Aunque la aldea de Pétzal no cuenta aún con el número de habitantes que prescribe el inciso $1 .^{\circ}$ artículo 4. ${ }^{\circ}$ de la ley de Municipalidades, esa Aldea es de bastante importancia, tanto porque la mayor parte de sus habitantes corresponde a la clase ladina, como por que es considerablemente rica en sus producciones agrícolas. La Municipalidad de Colotenango a que Pétzal corresponde está compuesta de indígenas que ni aún siquiera saben el castellano y esa circunstancia no ha dejado ni deja de ser un obstáculo respecto de los asuntos públicos i privados de la expresada Aldea, dando esto lugar muchas veces a que las autoridades superiores tengan que entenderse directamente con el alcalde auxiliar que allí funje. ${ }^{29}$
\end{abstract}

Para entonces, el máximo cargo al que podían aspirar los ladinos de Pétzal era el de alcalde auxiliar de la aldea, lo que les parecía absolutamente insuficiente. Era obvio que en este caso, el Estado prefirió favorecer la segregación territorial antes que la instauración de una alcaldía mixta. ${ }^{30}$ De hecho, los ladinos petzaleños nunca la solicitaron sino que prefirieron deshacerse del poder local mam, fuertemente defendido en Colotenango.

En todo el proceso de segregación queda claro que, al amparo de las autoridades políticas y judiciales y a pesar de que no se llenaban los requisitos para el cumplimiento de la ley, el movimiento segregacionista prosperó, pues tenía las características que al Estado liberal guatemalteco le interesaba favorecer: un municipio manejado por ladinos que eran propietarios particulares y milicianos del régimen, en una zona mayoritariamente mam, en momentos ya de expansión cafetalera y de plena aplicación del proyecto de modernización liberal.

De esta manera, el 21 de mayo de 1890, por acuerdo gubernativo se ordenó la segregación, creando el municipio de San Rafael Pétzal. Dicho acuerdo ordenó dividir el municipio de Colotenango en dos, lo que implicó reiniciar el proceso de medición para establecer los límites entre ambos municipios, así como aquéllos entre tierra ejidal 
y excesos. De las 220 caballerías que medía Colotenango había que deducirle 76 de ejidos para ambos pueblos, por lo que quedaban 144 de excesos, la mitad para cada pueblo. Tuimaché era uno de esos excesos y, como hemos visto, fue vendido en pública subasta siguiendo la política de privatización liberal, pues "no es conveniente a los intereses generales la existencia de comunidades"31.

El agrimensor fue el ingeniero Diego Vásquez, quien al tratar de fijar el límite entre los dos pueblos se encontró con la férrea oposición de los mames de Colotenango, los que querían que se incluyera en su municipio la aldea Xémal, pues esos terrenos

eran de la propiedad de hijos de Colotenango, que no querían someterse a la jurisdicción de San Rafael, cuyas autoridades — decían — eran muy tiránicas con los naturales, de quienes exigían contribuciones y trabajos que los abrumaban, obligándoles a abandonar para siempre sus hogares, como que en efecto se verán muchos ranchos sin habitantes. ${ }^{32}$

El Estado apoyaba la causa de los petzaleños, lo que provocó un alto grado de conflictividad en la zona. Años después, en un memorial fechado en 1933, el alcalde $2 .^{\circ}$ de Colotenango, el mam Diego Morales, explicaba que "San Rafael es una finca o aldea, el litigio obedece a que el señor don Tiburcio Molina, según creemos, sin ningún derecho vendió nuestras tierras a los propietarios de San Rafael”33.

Para los mames era claro que vivían la ambigüedad —o duplicidad— de si Pétzal era propiedad privada o una unidad político-administrativa; de si era finca o aldea. 


\section{LA RESISTENCIA MAM: CONFLICTO JURISDICCIONAL}

\section{EN TORNO A LA ALDEA XÉMAL}

Desde el momento de la segregación, la oposición de los mames de Xémal de pertenecer a San Rafael Pétzal fue constante, pues acusaban a esos ladinos — que controlaban la municipalidad recién creada— de querer usurparles las tierras, "con el objeto de ir agrandando su jurisdicción valiéndose de audacias"34. El siguiente memorial, presentado en 1896 por los mames de Xémal al presidente de la República, expresa claramente por qué no querían depender de San Rafael:

La aldea de Pétzal, pueblo de San Rafael, se compone tan solo de una generación de Aguirre que nunca está en paz ... que por razón de ser indígenas sencillos somos sus víctimas a cada poco tanto en nuestras personas como en nuestros intereses ... la autoridad de San Rafael que no cesa de molestarnos con prisiones injustas ... Si alguno de nosotros debe llegar al Juzgado de San Rafael porque se nos necesita para algo no se nos llama, se manda una escolta que va bien armada y con fuerza allana nuestras casas y si no estamos en ellas ultrajan a nuestras familias y las amenazan con las armas ... y todo sin que seamos delincuentes. Muchos vecinos de las aldeas se han marchado ya temerosos de la indignidad con que se nos trata y su proceder no obedece a otra mira que la de desesperarnos, para que dejemos nuestras tierras y puedan libremente los señores de San Rafael dividirse lo que ha sido nuestro humilde patrimonio. Para salvar esos apuros damos por fin el resultado de que somos esclavos, que por la fuerza debemos trabajar para que sea pueblo San Rafael por más que su posición topográfica no merezca tan hermoso título pues está situado a la falda de un cerro que no se presta para ninguna mejoría local. Señor, nuestros servicios concejiles, impuestos municipales y demás tequios de pagar todo vecino los damos con entera voluntad a nuestro antiguo por inmediato pueblo de Colotenango; ¿por qué se nos quiere someter por la fuerza a formar parte de la colectividad de San Rafael, cuando para nosotros es tan odioso por las innumerables desgracias que nos están originando? Creo encontramos la razón que se tenga para ello porque si bien somos indígenas ambicionamos vivir en paz y no envueltos en enredos que no sirven más que para [que] la autoridad nos esquilme. Por estas razones, Señor General Presidente, pedimos y suplicamos humildemente se nos conceda segregarnos de San Rafael para que nos incorporemos a nuestro antiguo y primogénito pueblo de Colotenango... ${ }^{35}$ 
O sea, por los abusos de autoridad de la familia Aguirre, cuyos miembros les quitaron sus tierras y los obligaban a trabajar para aquéllos.

Meses después, la jefatura política de Huehuetenango, a través de su secretario Luciano Aguirre - hermano del estanquero Víctor Aguirre de Colotenango y otros pueblos vecinos, e hijo de quien fuera alcalde de Pétzal, Francisco Aguirre Maldonado-, informaba que los vecinos de Xémal siempre se habían opuesto a ser de San Rafael, evadiendo la acción de las autoridades del pueblo cuando les exigían hacer trabajo personal en las obras públicas:

... pues por el contrario se hace más patente su odio contra los ladinos de San Rafael, y de temerse es que en un momento dado ocurran algunas desgracias, y que llegado el caso los indígenas de este último pueblo se les unan, por la mala prevención que esa parcialidad mantiene contra los ladinos, lo cual reconocen sobradamente, sin que la autoridad política y militar pueda darles inmediato auxilio por la distancia en que se encuentran y porque no hay en una localidad, ni inmediata a ella, oficina telegráfica. ${ }^{36}$

Cuarenta y tres años pasaron en esa situación de litigio hasta que el 17 de octubre de 1933, atendiendo la demanda de los mames de Xémal, el general Ubico emitió un acuerdo gubernativo ordenando que la aldea fuera traspasada a la jurisdicción de Colotenango. ${ }^{37}$ No obstante, el 27 de agosto de 1934, el alcalde 1. ${ }^{\circ}$ de San Rafael, Gerardín Aguirre, manifestó al ministro de Gobernación y Justicia que "esta Municipalidad y Vecindario, de ninguna manera consentirá voluntariamente que el síndico otorgue, como lo solicita la Municipalidad de Colotenango, escritura traslativa de dominio de la superficie de terreno en la cual se asienta la aldea XEMAL"38 y pidió permiso para hacer una colecta en todo el vecindario destinada a recaudar fondos para 
financiar el litigio legal por Xémal, pues no estaban conformes con el acuerdo gubernativo de 17 de octubre de 1933.

Cuando el dictador vio la rebeldía local ladina, ordenó anexar a Colotenango no solo la aldea Xémal sino también el municipio de San Rafael Pétzal, regresándolo a su categoría original de aldea dependiente de la municipalidad de Colotenango. Era el 11 de diciembre de 1935. A diferencia del apoyo estatal que habían recibido los ladinos petzaleños en 1890 para controlar la municipalidad separándose de Colotenango y creando un nuevo municipio, con el presidente Ubico el Estado se les volteó. Era parte de la estrategia ubiquista de castigo a los ladinos locales que provocaban alta conflictividad en las áreas rurales; estrategia destinada a incrementar el control estatal en el campo y centralizar su poder presidencial.

Los ladinos petzaleños nunca aceptaron volver a ser una aldea de Colotenango y solicitaron una y otra vez recuperar la categoría de municipio. Petición que recibió incluso el apoyo de los habitantes de Xémal y El Chorro —caserío perteneciente a la aldea Xémal-, con tal que ellos pudieran quedarse del lado coloteco y ya no tener ninguna relación político-administrativa con San Rafael Pétzal. Así se expresaban en 1946 los principales de El Chorro y Xémal acompañados por un “considerable número de vecinos", ante la corporación municipal de Colotenango:

[los vecinos de esas aldeas] jamás han deseado pertenecer a aquel lado. Continúan los mismos expresando que, tanto los vecinos de una y de la otra aldea, ni siquiera han vuelto a pensar en el "viejo asunto, que de viejo está sancionado", que es muy posible que los petzaleños no conformes nunca con haberlos reducido injustamente a aldea, traten de escarbar viejas cuestiones para abrirse paso para el restablecimiento de su antiguo municipio. "Siguen los exponentes": que 
tanto los vecinos de las aldeas cuestionadas como los vecinos de este municipio en general, verían con sumo agrado y sin reparar en cosas de antaño, que la fracción de San Rafael Pétzal lograra formar de nuevo su municipio, ya que franca y categóricamente aquellos se han visto seriamente perjudicados en sus intereses y en todo lo demás a causa de aquella disposición, la que por otro lado, tampoco ha sido en beneficio de esta población máximo si ha de tenerse bien protegidos los edificios públicos que son de alguna importancia para el lugar y sus propios vecinos pero no llenarían un objetivo principal para este pueblo, como era el agua potable y algunas otras atenciones de importancia que hay que presentarle a dicha aldea. ${ }^{39}$

En 1947, ya bajo el gobierno revolucionario de Juan José Arévalo, cuya base social era eminentemente ladina, San Rafael Pétzal recuperó su categoría de municipio, quedando por resolver el traspaso de Xémal a la jurisdicción de Colotenango.

En 1953, en otra sesión municipal en Colotenango, se informó que todavía no había sido posible concluir el expediente de titulación de la aldea Xémal, iniciado cinco años antes. Los vecinos atribuían el atraso a la municipalidad de San Rafael Pétzal, controlada por los ladinos, pues "los vecinos de la aldea se consideran amenazados de ser absorbidos por San Rafael Pétzal, que se cree con derechos y ya tiene entendido de que de ser así, las consecuencias serían fatales y lamentables para los incidentes que llegaren a resultar, ${ }^{\circ 0}$. Por tanto, solicitaron a la municipalidad de Colotenango que asignara un síndico para que hiciera las gestiones pertinentes ante la Sección de Tierras. Finalmente el 16 de octubre de ese año fue emitido un acuerdo gubernativo según el cual se aprobaba el expediente de segregación de la aldea Xémal del municipio de Colotenango que "indebidamente se encontraba incluido en los títulos ejidales de San Rafael Pétzal”41. Para entonces habían pasado sesenta y tres años de trámites.

En 1961, el alcalde de Colotenango insistió en la aplicación de los acuerdos gubernativos emitidos por los presidentes Ubico y Arbenz favorables de la inclusión de 
Xémal a ese municipio, elevándose el asunto al Juzgado de $1 .^{\mathrm{a}}$ Instancia Departamental $^{42}$. Cuatro años más tarde, la Sala 7. a de la Corte de Apelaciones en el juicio ejecutivo contra San Rafael Pétzal, revocó el punto 2. ${ }^{\circ}$ de la sentencia dictada por el Juzgado de $1 .^{a}$ Instancia Departamental en el que obligaba a la municipalidad de San Rafael Pétzal otorgar escritura traslativa de dominio de la aldea Xémal en favor de la municipalidad de Colotenango. Al ser revocada esa sentencia, la municipalidad coloteca volvió a apelar; pues Xémal es una

aldea que por muchísimos años ha pertenecido a este municipio y sus vecinos aquí prestan su trabajo personal voluntario, aquí contribuyen con su ornato, se reconocen como legítimos colotecos y, en fin, por derecho y en derecho los terrenos de dicha aldea deben quedar incluidos en el título general de este pueblo. ${ }^{43}$

En el año 2001 don Herculano Molina, ladino coloteco, quien fue secretario de la municipalidad de su pueblo durante treinta y cinco años y alcalde en una ocasión, describía así el conflicto añejado entre Xémal y San Rafael Pétzal:

Fíjese que Xémal, según los documentos del municipio de San Rafael, pertenece a San Rafael Pétzal; no está desmembrada del título de San Rafael. Hay un Acuerdo del tiempo de Arbenz donde dice que los terrenos de Xémal pasen a la municipalidad de Colotenango, pero la municipalidad de San Rafael Pétzal tiene que otorgar una escritura de propiedad a la municipalidad de Colotenango. Una vez intentamos, ya tiene años, y nos fuimos a platicar con el alcalde de San Rafael, pero se iban a crear conflictos con el pueblo. Los de Xémal son de Colotenango, a ellos no les hace ser de San Rafael. Hay una guerra entre los dos. Ellos ya se reconocen como colotecos, Xémal. Les dicen "miren, ustedes, van a pertenecer a San Rafael Pétzal”, pues no. Pero documentalmente Xémal pertenece a San Rafael. Y no logramos que la municipalidad de San Rafael Pétzal otorgara su traspaso a la municipalidad de Colo[tenango]. Fuimos a dialogar con el alcalde; esa vez nos estaba pidiendo el alcalde $\mathrm{Q} \$ 600.00$ de mordida para hacer el traspaso. Q\$600.00 eran miles a principios de los años 60. Intentamos, nos vamos a aventurar y esa fue la reacción del alcalde. Nosotros no pudimos porque $\mathrm{Q} \$ 600.00$ eran miles y las municipalidades eran raquíticamente pobres. ${ }^{44}$ 
En resumen, los pobladores mames de Xémal se opusieron insistentemente a la hegemonía de los ladinos que les quitaron las tierras y los sujetaban laboralmente, centrando la batalla en lograr su independencia administrativa pues eran ellos los que, además, controlaban el poder municipal de San Rafael Pétzal. Era su única estrategia posible en un universo en el que los intereses privados y la práctica pública, expresada a través de la institucionalidad republicana, se entremezclaban. El caso de los Aguirre permite develar precisamente la vinculación entre sujeción laboral, propiedad de la tierra, ocupación de cargos públicos, y ordenamiento territorial. Veamos.

\section{SUJECIÓN LABORAL Y HEGEMONÍA LADINA EN UN MUNDO MAM}

Según la memoria de los mames colotecos entrevistados, remontándose a la época de Ubico, los habilitadores para las fincas de café eran para entonces sobre todo ladinos, generalmente de los pueblos vecinos. De los 43 nombres de habilitadores que aparecen registrados en los cuadernos de control de mozos de la municipalidad de Colotenango para los años de 1943 a 1947, 39 pertenecen con seguridad a personas ladinas —36 hombres y 3 mujeres - mientras que, al leer los apellidos, 4 podrían ser mames.

Entre los primeros se encuentra Gerardín Aguirre, de San Rafael Pétzal, quien en 1934 fue alcalde de ese pueblo y era habilitador de mozos mames en Xémal y El Chorro. El mismo caso es el de Salomón Villatoro, alcalde de San Rafael Pétzal en 1933 y habilitador de mozos en San Rafael Pétzal y Xémal. O el de Rafael Ríos, secretario de la municipalidad de Colotenango en 1933 y habilitador de mozos mames colotecos. ${ }^{45}$ 
Sobre Gerardín Aguirre, un hombre mam de San Rafael Pétzal opinaba que era "el rey del pueblo": los dueños del municipio eran los ladinos, porque antes su pueblo era aldea, pero que éstos, “dueños de las tierras y de los aguardientes”, lo convirtieron en pueblo. ${ }^{46}$ Por su parte, un ladino de Colotenango hablaba así de sus pares petzaleños:

\footnotetext{
[los ladinos] eran caciques, más bien dicho, caciques. Ellos mandaban pues a las comunidades esas, como antes la gente indígena era domada, muy domada, para en cuestión de una elección lo que decía el cabecilla, ahí iban todos, todos. Hoy no, como consecuencia de las escuelas ya la gente está muy despierta, y ya no hay necesidad de que uno les diga: "mirá, yo voy a hacer esto, cuando esté en el cargo voy hacer esto otro". Ellos analizan ya, aunque sean indígenas ya ellos analizan, ya saben por quién van a votar, ya tienen ellos en su mente. Y como consecuencia de eso fue que San Rafael y San Gaspar se independizaron. Tenían mucha tierra, pura caña, los Aguirre también, Romeo Aguirre, Gerardín Aguirre, esos eran los caciques. ${ }^{47}$
}

El primer miembro de la familia Aguirre del que hay constancia en Huehuetenango es Felipe, quien de 1763 a 1804 ocupó los siguientes cargos: maestro en San Juan Ixcoy y San Mateo Ixtatán, cabo de escuadra y sargento en la Compañía de Huehuetenango, responsable del cuidado de peste en Jacaltenango, Soloma y Todos Santos, receptor de alcabalas, juez preventivo, encargado de agricultura y comisionado de Jacaltenango, juez territorial en Soloma, y apoyo de los celadores de tabaco en la zona. ${ }^{48}$ Después de todos estos años de funcionario en los pueblos indígenas del altiplano huehueteco, en 1837 poseía ya casa en la cabecera departamental.

En 1855 su hijo Bernardino Aguirre era propietario de tierras en la aldea Pétzal, donde cultivaba caña. Serían los hermanos Francisco, José Exequiel, Luis y Jesús —hijos de Bernardino Aguirre y Simona Maldonado, ${ }^{49}$ y nietos, por lo tanto, de Felipe Aguirre y María Trinidad López - quienes protagonizaron la dinámica político-económica de 
Pétzal en el periodo señalado, junto con el resto de ladinos emparentados entre sí. Todos eran propietarios de tierras en la zona, en las que cultivaban caña de azúcar mediante mozos mames. Se fueron turnando en los cargos de alcalde auxiliar cuando Pétzal era aldea y de alcalde municipal cuando lograron crear el municipio de San Rafael Pétzal. Además, algunos de ellos eran habilitadores de los mames colotecos hacia las fincas cafetaleras de la bocacosta, pues contaban con la fuerza laboral de aquellos que habían poseído tierras que ahora eran propiedad de los Aguirre. Algunos datos biográficos más de los Aguirre permiten entender su empresa familiar.

En 1917 José Exequiel Aguirre Maldonado inscribió en el segundo Registro de la Propiedad Inmueble tres propiedades urbanas en San Rafael Pétzal y cinco rústicas en el mismo municipio. En 1906 le había comprado al coronel Tiburcio Alejandro Molina la parte occidental de la finca Cruz Quemada, declarada exceso junto con Tuimaché cuando se segregó Pétzal. ${ }^{50}$ También hay constancia en el segundo Registro de la Propiedad Inmueble de que poseía lotes de terreno en Xémal, comprados a vecinos mames. Fue alcalde auxiliar de la aldea Pétzal en 1880 y, posteriormente, alcalde $1 .^{\circ}$ de San Rafael Pétzal en 1895 y 1897, ${ }^{51}$ entonces le correspondió firmar las dos solicitudes de segregación de Pétzal de 1884 y 1889.

En 1881, Francisco Aguirre Maldonado era alcalde interino de la aldea Pétzal, para luego serlo oficialmente en 1891 y en $1894,{ }^{52}$ cuando se midió el ejido del pueblo. Asimismo, firmó las solicitudes de segregación de Pétzal en 1884 y 1889. Según el segundo Registro de la Propiedad Inmueble poseía catorce propiedades urbanas en San Rafael Pétzal y nueve rústicas en el mismo municipio; de las primeras, ocho fueron 
hipotecadas entre 1926 y 1943 a favor de Moesly y Cía, compañía suiza con fincas cafetaleras en la bocacosta.

La acción de los ladinos locales — como muestra el caso de la familia Aguirre— se centró en ir utilizando las ventajas que el Estado les facilitaba legal y tácitamente para apropiarse de los recursos locales de los mames: acceso a los mecanismos de registro de tierras ya ocupadas, control de la actividad comercial más lucrativa de la zona, acceso a cargos públicos locales, nexos con cargos político-militares regionales o nacionales. El Estado impulsó así procesos de expropiación y desarticulación de los patrimonios colectivos de forma "sutil", mientras que los ladinos tuvieron la sagacidad suficiente para aprovechar la legislación vigente y apropiarse del máximo posible de recursos.

Con la articulación de estos territorios a la economía cafetalera, la situación de los campesinos mames adquirió dimensiones dramáticas a partir de la intervención de dispositivos estatales dirigidos a la movilización de la fuerza laboral; los que se sumaban a las contradicciones generadas en etapas anteriores. Esta articulación se realizó a través de múltiples mecanismos que consolidaron la ruptura de cualquier posibilidad de autonomía económico-social de estos municipios marginales.

Los ladinos locales se incorporaron al sistema de trabajo forzado a partir de tener acceso a puestos que les daba el Estado, como autoridades municipales/departamentales y milicianos, y de integrarse a la iniciativa privada que los empleaba como habilitadores. Y si bien los grandes finqueros cafetaleros fueron sobre todo extranjeros, cabe mencionar que los primeros expropiadores de tierras resultaron guatemaltecos, quienes 
vendieron esas tierras a los extranjeros que tenían mayor acceso a créditos y facilidades comerciales, especialmente aquellos de origen alemán.

\section{CONCLUSIÓN}

Las fincas de mozos eran - y aún siguen siendo — una de tantas formas de coacción extraeconómica que ha marcado la historia de las relaciones laborales en Guatemala. Como bien afirma David McCreery, ${ }^{53}$ la dominación de la economía local por un capitalismo externo a Guatemala, ya fuese con el auge cacaotero de los siglos XVI y XVII o el de café en el XIX, tuvo el efecto de fortalecer en lugar de debilitar las relaciones laborales precapitalistas en el campo. La coacción directa se mantuvo durante casi toda la primera mitad del siglo XX, y cuando en la década revolucionaria 1944-54 se legisló favorablemente la libertad laboral la coacción ya no era tan necesaria, pues la pérdida progresiva de los recursos comunitarios que garantizaban su reproducción convirtieron a las comunidades en dependientes de los jornales de las fincas por necesidad económica.

A pesar de ello, la sujeción laboral persiste, como ocurre entre los habitantes de Xémal: unos, los mozos de la finca La Sierra, condicionados por la necesidad de tierra; otros, los pobladores de Xémal, obligados a cambio de tener acceso al agua que pasa cerca de sus plantíos. La misma lógica liberal de "estrangular" la capacidad de reproducción comunitaria quitándoles sus medios de producción para convertirlos en mozos “disponibles" se mantiene. 
David McCreery nos ofrece el primer estudio detallado, amplio y analítico sobre la estructura y modalidades de funcionamiento del sistema de trabajo forzado y sus implicaciones para las comunidades indígenas del altiplano guatemalteco. Hasta ese momento, los estudios realizados se habían centrado más en su análisis desde el Estado, los finqueros y las zonas de grandes fincas, entre los que destaca la obra de Julio Castellanos Cambranes. McCreery establece una relación directa entre el proceso de expropiación de tierras y el trabajo forzado, con lo que abre líneas para multiplicidad de estudios —y señala la necesidad de hacerlos— que contrarresten las visiones más macro con perspectivas locales y regionales que esbocen el desigual desarrollo del proyecto capitalista, creador de desigualdades territoriales.

A ese esfuerzo - $-\mathrm{y}$ nutriéndose de él— se suman aportes de antropólogos, los que, viniendo de la tradición norteamericana culturalista más interesada en el estudio de alguna comunidad indígena, logran ponerlo en relación con la dinámica histórica nacional. Por ejemplo John Watanabe y Shelton Davis se centran en el análisis de diferentes municipios de Huehuetenango. Ambos ponen énfasis en la cuestión de la tierra y sus implicaciones en la cultura y en el poder local.

Los estudios particulares permiten ir constatando que todas las comunidades indígenas fueron afectadas por las disposiciones estatales, variando la intensidad del impacto sufrido y el grado o los modos de oposición de cada una de ellas. Esa diversidad queda reflejada en los estudios sobre localidades indígenas realizados, en los que, dentro del objetivo más amplio de explicar la dinámica global de un municipio del altiplano, exploran el eje tierra-trabajo-poder en el periodo liberal. El primer gran esfuerzo fue el 
del historiador francés Jean Piel, al que le han seguido, entre otros, los de Matilde González y Edgar Esquit, historiadores guatemaltecos.

El presente trabajo pretende coadyuvar a la línea esbozada de documentar la diversidad local para entender la complejidad de la realidad estatal, pero partiendo de la hipótesis de la estrecha vinculación existente entre los tipos de acción política en el ámbito municipal —desde quién ocupa los cargos ediles hasta cuáles son sus límites jurisdiccionales - y el funcionamiento de un proyecto económico estatal. En ese proyecto, la disputa por los recursos locales — concretamente la tierra y la fuerza laboral- estaban estrechamente ligados entre sí, generando una realidad de polarización y conflicto en todos los ámbitos de la vida del municipio.

Los campesinos del área estudiada acumularon años de experiencia en resistir, y lo hicieron defendiendo el único espacio al que tenían acceso: su autonomía comunitaria, que en el caso de Xémal se concretaba en pertenecer a la jurisdicción municipal de Colotenango. La tenacidad en oponerse durante casi cien años a quedar jurídicamente ligados a las autoridades municipales petzaleñas que los sojuzgaban laboralmente, muestra cómo la construcción de la hegemonía ladina en estas zonas no fue un proceso lineal sino insistentemente contestado y resistido. 


\section{BIBLIOGRAFÍA}

Siglas de Archivos

AGCA: Archivo General de Centroamérica, en Guatemala.

AMC: Archivo Municipal de Colotenango.

RPIQ: 2. ${ }^{\circ}$ Registro de la Propiedad Inmueble, en Quetzaltenango.

Material Hemerográfico

Diario La República, Guatemala, 1907, 1910

Publicaciones

Arzú Batres, Joaquín, 1907, “Calamidades Sociales. Indios y ladinos”. La República, año VII, 2. á Época, 15 mayo , núm. 4554. Guatemala.

Barrios, Lina, 2001, Tras la huella del poder local: la Alcaldía Indígena en Guatemala, del siglo XVI al siglo XX. Universidad Rafael Landívar, Guatemala.

Castellanos Cambranes, Julio, 1985, Café y campesinos en Guatemala, 1853-1897. Ed. Universitaria, Guatemala.

Davis, Shelton H., 1997, La tierra de nuestros antepasados. Estudio de la herencia y la tenencia de la tierra en el altiplano Guatemalteco. CIRMA-Plumsock Mesoamerican Studies, Guatemala-EEUU. 
Esquit, Edgar, 2002, Otros poderes, nuevos desafíos. Relaciones interétnicas en Tecpán y su entorno departamental (1871-1935). IDEI, Guatemala.

González, Matilde, 2002, Se cambió el tiempo. Conflicto y poder en territorio quiché 1880-1990. Asociación para el Avance de las Ciencias Sociales (AVANCSO), Guatemala.

Jiménez, Lizeth, 1995, Metodología de la recuperación participativa de la historia. El Temal. FIA-SAL/CAOBA, Guatemala.

McCreery, David, 1983, "Debt Servitude in Rural Guatemala, 1876-1936”. Hispanic American Historical Review, núm. 63 (4), Department of History, University of Maryland.

1994, Rural Guatemala 1760-1940. Standford University Press, Standford.

2001, "Mano de obra asalariada, trabajo libre y leyes contra la vagancia: la transición al capitalismo en Guatemala". En Cafe, sociedad y relaciones de poder en América Latina, compilado por Mario Samper, William Roseberry y Lowell Gudmundson, pp. 346-383. Editorial Universidad Nacional, Costa Rica.

Méndez, Rosendo, 1927, Leyes vigentes. Tipografía Nacional, Guatemala.

1936, Recopilación de las Leyes de la República de Guatemala 1933-34, tomo 52. Tipografía Nacional, Guatemala. 
NACLA, 1978, “La tierra, cuestión radical: La formación del capitalismo dependiente agroexportador en Guatemala: La familia Herrera”. ECA, junio-julio. El Salvador.

Palma, Gustavo (coord.), 1998, Historia de la administración político-territorial en Guatemala. Universidad de San Carlos de Guatemala, Guatemala.

Piel, Jean, 1989, Sajcabajá. Muerte y resurrección de un pueblo de Guatemala, 15001970. Seminario de Integración Social-CECMA, Guatemala-México.

Samayoa Coronado, Francisco, 1964, La Escuela Politécnica a través de su historia, tomo I, Tipografía, Guatemala.

Taracena, Arturo, 1997, Invención criolla, sueño ladino, pesadilla indígena. Centro de Investigaciones Regionales de Mesoamérica (CIRMA), Guatemala.

Tejada, Mario, 2002, Historia social del Norte de Huehuetenango. Centro de Estudios y Documentación de la Frontera Occidental de Guatemala (CEDFOG), Guatemala.

Wagner, Regina, 1996, Los alemanes en Guatemala 1828-1944, Guatemala.

Watanabe, John, 2006, "Los que estamos aquí”. Comunidad e identidad entre los mayas de Santiago Chimaltenango, Huehuetenango, 1937-1990. CIRMA-Plumsock, Guatemala. 


\section{Notas}

1 Este artículo surge de la tesis de maestría en historia "Conformación de un municipio marginal guatemalteco: tierra, trabajo y poder en Colotenango (1825-1947)", Universidad de Costa Rica, 2005; y del trabajo de investigación realizado en el marco del Área de Estudios de Historia Local de la Asociación para el Avance de las Ciencias Sociales, en Guatemala.

${ }^{2}$ Entrevista I-2001. Nota: Para garantizar la seguridad de los entrevistados los nombres fueron cambiados por pseudónimos. Todas las entrevistas fueron realizadas en Colotenango, menos la K-2001 (nota 22).

${ }^{3}$ Nombre que adquirieron en Guatemala, sobre todo en el agro, las castas coloniales compuestas sobre todo por mestizos pero también por zambos, mulatos y criollos empobrecidos.

${ }^{4}$ Memoria de la Dirección General de Agricultura, 1902, pp. 35-45. Tipografía Nacional, Guatemala.

5 Arzú Batres 1907: 1.

${ }^{6}$ McCreery 1983: 740.

${ }^{7}$ NACLA 1978.

8 Jiménez 1995.

${ }^{9}$ González 2002.

10 Tejada 2002: 137

${ }^{11}$ AGCA. Sección Tierras. Decreto 900. Núm. 8. Paquete 7. Huehuetenango.

12 El coronel Tiburcio A. Molina compró las fincas Cruz Quemada y Tuimaché -ambos terrenos declarados excesos baldíos- para vender la primera a Luis Aguirre y la segunda a José Mathis. Además de las fincas mencionadas, poseía otro terreno en San Rafael Pétzal, dos casas en la ciudad de Huehuetenango y en 1901 se le adjudicó, por acuerdo gubernativo, otro terreno en San Miguel Uspantán (El Quiché). Sabemos que nació en La Antigua, ingresó a la Escuela Politécnica en 1883 egresando como alférez en 1887, alcanzó el grado de coronel, participando en las campañas de 1885 y de 1890; y a partir de ahí fue comandante de armas y jefe político de los Departamentos del Quiché, Huehuetenango y Alta Verapaz hasta ser nombrado en 1910, director general de policía. La República, Guatemala: 3 agosto 1910, p.1, "El Señor Director General de Policia"; Samayoa Coronado, Francisco, 1964, La Escuela Politécnica a través de su historia, tomo I, Tipografía, Guatemala, p. 117-118, 129-130, 142, 167, 212.

${ }^{13}$ Wagner 1996:140-141.

14 Íbid, p. 278.

15 Íbid, p. 261.

${ }^{16}$ RPIQ. Libro 13. Folio 80. Número 878, y Libro 47. Folio 93. Número 7668. Huehuetenango.

${ }^{17}$ AGCA. Sección Tierras. Decreto 900. Número 12. Paquete 7. Huehuetenango.

${ }^{18}$ AGCA. Sección Tierras. Decreto 900. Número 8. Paquete 7. Huehuetenango.

${ }^{19}$ AMC. Libro de Actas de Sesiones de la Municipalidad de Colotenango. Número 12. 18 agosto 1944.

${ }^{20}$ AGCA. Sección Tierras. Decreto 900. Número 8. Paquete 7. Huehuetenango.

${ }^{21}$ RPIQ. Libro 17. Folio 166. Número 1643. Huehuetenango.

${ }^{22}$ Entrevista K-2001; realizada en Chimaltenango

${ }^{23}$ AMC. Libro de Actas de Sesiones de la Municipalidad de Colotenango. Números 29-87. 18 diciembre 1987.

${ }^{24}$ La estructura político-administrativa de la Guatemala republicana quedó primeramente ordenada en 1825 en departamentos, subdivididos en distritos y éstos, a su vez, en municipios. En 1871, se reordenó el territorio manteniendo la lógica departamental, subdividida en municipios. Los municipios incluían la cabecera o pueblo y otras unidades de menor población dependientes de la primera que podían ser aldeas, caseríos, fincas o parajes. Las aldeas y en muchos casos las fincas contaban con alcalde auxiliar dependiente del alcalde municipal. Véase, Palma 1998.

25 AGCA. Protocolo Municipal Huehuetenango. Número 180. Años 1860-1865; AGCA. Sección Tierras. Paquete 20. Expediente 4, p. 73. Huehuetenango.

${ }^{26}$ Taracena 1997.

27 AGCA. B. Legajo 1335. Expediente 28708.

${ }^{28}$ Ídem.

${ }^{29}$ AGCA. B. Legajo 28793. Expediente 1669. 
${ }^{30}$ Las alcaldías mixtas en pueblos mayoritariamente indígenas empezaron con los primeros liberales; luego los conservadores (1838-71) establecieron una alcaldía ladina y otra indígena para un mismo pueblo. Los segundos liberales reestablecieron las alcaldías mixtas, primero en casos especiales con población ladina numéricamente importante y luego, a partir de 1927, se generalizaron a los pueblos con minoría ladina, disponiéndose que las municipalidades de poblaciones mayoritariamente indígenas fueran integradas por un alcalde $1 .^{\circ}$ y un síndico $10^{\circ}$ ladinos y alfabetas; el resto de la corporación se haría de forma que siempre quedaran representados por mitad los ladinos y los indígenas "prefiriéndose en la elección a los que hablen castellano, usen el traje de clase ladina y sepan leer y escribir". Todo ello "por estar comprobado con los respectivos datos estadísticos, que los pueblos cuyas municipalidades han venido integrándose con solo elemento indígena se han estancado en su marcha evolutiva...", Méndez 1927: 622, y Barrios 2001.

${ }^{31}$ AGCA. Sección Tierras. Paquete 20. Expediente 4. Huehuetenango.

32 Ídem.

33 Ídem.

34 Ídem.

${ }^{35}$ AGCA. B. Ministerio Gobernación. Legajo 28930. Expediente 2629.

${ }^{36}$ Ídem.

${ }^{37}$ Acuerdo Gubernativo número 2428. Méndez 1936.

${ }^{38}$ AGCA. B. Gobernación (Escribanía de Gobierno). Legajo 30982. Expediente 83.

${ }^{39}$ AMC. Libro de Actas de Sesiones de la Municipalidad de Colotenango. Número 5. 14 febrero 1946.

${ }^{40}$ AMC. Libro de Actas de Sesiones de la Municipalidad de Colotenango. Número 4. 18 febrero 1953.

${ }^{41}$ AMC. Libro de Actas de Sesiones de la Municipalidad de Colotenango. Número 16. 14 diciembre 1953.

${ }^{42}$ AMC. Libro de Actas de Sesiones de la Municipalidad de Colotenango. Número 10. 2 junio 1961.

${ }^{43}$ AMC. Libro de Actas de Sesiones de la Municipalidad de Colotenango. Número 14. 27 mayo 1965.

${ }^{44}$ Entrevista H-2001.

${ }^{45}$ Otros habilitadores, ladinos y ladinas, eran: Ángel M. ${ }^{\mathrm{a}}$ y Adrián Herrera, Baudilio y Ernesto Castillo, Juana A. de Aguirre, María C. de Aguirre, Armando, Augusto y Adolfo Villatoro, Antonio Ríos H., Carlos Calderón Aguirre.

${ }^{46}$ Entrevista J-2005.

${ }^{47}$ Entrevista L-2001.

${ }^{48}$ AGCA. Protocolo Municipal de Huehuetenango. Número 176. Años 1837 y 1837-1844.

49 AGCA. Juzgado Primera Instancia. Ramo Criminal. Índice número 126. Huehuetenango: Legajo 12. Expediente 18; Legajo 19. Expediente 2; Legajo 13. Expediente 42; Legajo 35. Expediente 43; Legajo 37. Expediente 3; Legajo 37. Expediente 4; Legajo 38. Expediente 2.

50 AMC. Remedición de Colotenango. Año 1917.

51 AGCA. Juzgado Primera Instancia. Ramo Criminal. Índice número 126. Huehuetenango: Legajo 19. Expediente 2; Legajo 35. Expediente 43; Legajo 37. Expediente 3.

${ }^{52}$ AGCA. Sección Tierras. Paquete 20. Expediente 4. Huehuetenango.

${ }^{53}$ McCreery 2001. 